\title{
Sacral neuromodulation - when and for who
}

\author{
Marcelo Mass-Lindenbaum ${ }^{1}$, D. Calderón-Pollak ${ }^{1}$, H. B. Goldman ${ }^{2}$, Javier Pizarro-Berdichevsky ${ }^{3,4}$ \\ ${ }^{1}$ Universidad de los Andes, Santiago, Chile; ${ }^{2}$ Glickman Urologic Institute, Cleveland Clinic, Cleveland, \\ OH, USA; ${ }^{3}$ Centro de Innovación en Piso Pélvico, Hospital Sótero del Rio, Santiago, Chile; ${ }^{4}$ Division de \\ Obstetricia y Ginecología, Hospital Sótero del Río, Pontificia Universidad Católica de Chile, Santiago, \\ Chile
}

\section{WHAT IS SACRAL NEUROMODULATION?}

Sacral neuromodulation (SNM) is a therapeutic technique that involves electrical stimulation to a sacral nerve root to modulate a neural pathway. It is a minimally invasive procedure with good long-term outcomes used to treat bowel and/ or bladder dysfunction (1).

SNM is currently offered to patients with idiopathic overactive bladder $(\mathrm{OAB})$ syndrome with or without incontinence, fecal incontinence (FI) and non-obstructive urinary retention (NOR), who have failed to respond to conservative or medical therapies, such as pelvic-floor physical therapy and behavioral changes, that are the treatments typically considered as the first approach (1).

It can also be used as a therapeutic option in both bladder pain syndrome and neurogenic lower urinary tract dysfunction (NLUTD) who are at low risk of upper urinary tract deterioration, but the evidence is still very limited (level III/ grade of recommendation C) (1).

\section{HOW IT IS THOUGHT TO WORK}

Normal urinary function is controlled by brain and other peripheral neurologic structures $(2,3)$. Recent studies with functional magnetic resonance imaging (fMRI) have shown that certain brain areas, considered to be associated with urinary symptoms and urge, are hyperactivated in patients with $\mathrm{OAB}$ (4-6). Adding to this, it was seen that brain activity in female patients with $\mathrm{OAB}$ who had received pelvic floor physiotherapy (PFPT), with successful results, differed from those women to whom PFPT was ineffective in fMRI (7).

It is thought that SNM modulates neural circuits in both central and peripheral pathways, though its mechanism is not completely elucidated. This was made evident after fMRI revealed real-time changes in brain activity of $O A B$ patients who had received SNM, supporting the idea that SNM functions in part, through regulations in some pathways of the central nervous system (7). Additionally, with altered stimulus intensity, an amplitude-response association was found in various cerebral locations. What still remains unclear is how normalization of the lower urinary tract function relates to brain activity changes with SNM (7).

There are currently two hypotheses to understand SNM's therapeutic mechanism (7).

The first one, suggests that SNM produces afferent activity that overrides or interferes with the aberrant neural activity underlying $\mathrm{OAB}$, similar to how noise-cancelling headphones can allow soft music to be heard in a noisy environment (7).

A second theory states that it produces neuro-modulation, which could alter the set-point for voiding in brain centers that coordinate lower urinary tract function, similar to how a thermostat can be adjusted to maintain a comfortable tempe- 
rature. In $\mathrm{OAB}$, this set-point is likely miscalibrated, underlying the disease state (7).

\section{CURRENT INDICATIONS}

SNM indications for $\mathrm{OAB}$ are as follows per American Urologic Association (AUA) and International Continence Society (ICS) guidelines:

According to AUA "Clinicians may offer sacral neuromodulation as third-line treatment in a carefully selected patient population characterized by severe refractory $\mathrm{OAB}$ symptoms or patients who are not candidates for second-line therapy and are willing to undergo a surgical procedure. Recommendation (Evidence Strength Grade C)" (8).

According to ICS "SNM can be offered to patients with $\mathrm{OAB}$ with or without incontinence who fail to respond to or are intolerant of conservative and medical therapies. (Level of Evidence: I; Grade of Recommendation: A)" (1).

It is very important to note that $\mathrm{OAB}$ can present itself with or without incontinence. This can lead to a classification of OAB into "dry" and "wet".

In the case of $\mathrm{OAB}$ without incontinence or "dry", the ICS quotes a randomized, prospective, 12 center study which enrolled 51 patients who had $\mathrm{OAB}$ "dry" or a severe urgency-frequency syndrome. In this study, patients who showed a satisfactory response to peripheral nerve evaluation (PNE), which is a trial with a temporary sacral lead, where assigned randomly to immediate treatment or to the control group that consisted of implant after a delay of 6 months.

After 6 months, voiding diary results showed improvements that were statistically significant in the immediate implant group, as to degree of urgency, number of daily voids and volume per void, in comparison to the control group (9).

In another study that had 2 year follow up, 29 patients with urgency- frequency syndrome (or $O A B$ "dry") showed a significant reduction in the total of voids per day, with 56\% of them showing a reduction of $50 \%$ or more in their average voids per day (10).

In the case of $\mathrm{OAB}$ with incontinence or $\mathrm{OAB}$ "wet" SNM also showed positive results at medium and long terms.
A prospective, multicenter, randomized trial included 34 patients with severe $\mathrm{OAB}$ "wet" (urge-incontinence) who had an immediate implant after a positive trial test; and 42 patients as controls who received only standard medical therapy for 6 months and then had the device implanted (delayed group).

After 6 months, the immediate implant group showed a significant reduction in number of UI episodes, severity, and number of daily diapers or absorbent pads replaced, compared to the control group.

In the immediate implant group, $16(47 \%)$ patients were completely dry and 10 (29\%) other patients showed a $>50 \%$ reduction in UI episodes at 6 months of follow-up (11). After 18 months, the efficacy of the treatment remained high and surgical revision was required in 32.5\% of the patients.

Around $10 \%$ of the patients had to have a device explant because of lack of efficacy, bowel dysfunction or pain. No permanent therapy-related injuries were reported (11).

After 3 years, symptoms like leaking were significantly reduced with $59 \%$ of the patients reporting a $\geq 50 \%$ reduction in leaks per day and $46 \%$ of the patients reported being completely dry (10).

A study with a median follow-up of 50.7 months reported a success rate of $84.8 \%$ for UUI. In this study $39 \%$ of patients needed revision of the SNM neuromodulation implant (9).

At 6 months, SNM showed superior objective and subjective results compared to standard pharmacologic treatment for $\mathrm{OAB}$.

SNM is shown to be a safe and effective treatment for $\mathrm{OAB}$ patients (10).

In 2009, a Cochrane review concluded that implantable neurostimulators have benefits for some patients with $\mathrm{OAB}$ symptoms, retention without organic obstruction, and in those for whom other methods of treatment have failed (12).

In 2016, the ROSETTA trial, a multicenter randomized trial with 381 patients, that compared SNM with Onabotulinumtoxin A as a treatment for refractory UUI, showed a slightly greater improvement of daily UUI episodes in the Onabotulinumtoxin A compared to the SNM group, but the need for intermittent catheterization and UTI 
episodes were more frequent in the Onabotulinumtoxin A group (13). However, this study has been criticized by many as the dose of Onabotulinumtoxin A utilized was twice the standard approved dose and the SNM lead that was utilized is an older one that is no longer used. This may account for some of the improved efficacy of Onabotulinumtoxin A.

A more recent trial, the ARTISAN trial, with 129 patients, showed that $90 \%$ of the patients had a $\geq 50 \%$ reduction of daily UUI episodesat 6 months follow up.

In the cited trial, the mean UUI episodes were reduced from approximately 5.6 episodes per day, to approximately 1.3 (14).

Considering all of the above, SNM is shown to be a safe and effective treatment for $\mathrm{OAB}$ patients (10).

\section{SNM indications for Idiopathic non-obstructive retention (NOR) are as follows per ICS guidelines:}

"SNM is an effective treatment for Fowler's Syndrome, voiding dysfunction and NOR. (Level of Evidence: I; Grade of Recommendation: A)" (1);

"In general patients with NOR, usually confirmed with urodynamics, are offered to use intermittent self-clean catheterization. However, some patients are not able to do so or are not satisfied with this option. In these patients SNM should be considered as an option" (1).

A prospective, randomized study that included 12 centers and 177 patients with NOR, demonstrated a 71\% clinical success rate after 5 years of implantation of the SNM. All patients had a PNE, and 38.4\% received the implant. Of the 68 patients who qualified for implantation, 37 were randomly assigned to an immediate treatment and 31 to a 6-month delayed implant (control group). After 18 months, 70\% of the patients who had received the implant (immediate or late), showed more than 50\% reduction in volume per catheterization. Further publications showed that 69\% of the patients treated with implants eliminated catheterization at 6 months and an additional 14\% had more than a 50\% reduction in volume per catheterization. After 6 months, successful results were achieved in $83 \%$ of the implant group with
NOR in comparison to $9 \%$ of the control group.

Adding to this, a short-term inactivation of SNM showed a significant increase in residual volumes (15). A 5-year follow-up evidenced an important reduction in the mean volume per catheterization and of the mean number of catheterizations $(15,16)$.

A single center study showed a spontaneous voiding rate of $72 \%$ out of 60 patients implanted, over a follow-up of 4 years. After the procedure, of the 43 women who voided, only 13 required the continued use of intermittent self-catheterization twice a day, but this still was less than before the surgery. Patients who had abnormal sphincteric EMG before surgery had better results, with $76 \%$ of them experiencing complete restoration of voiding (17). Another study concluded that Fowler's syndrome is a positive predictive factor for SNM in female urinary retention (18).

Various single-center studies reported satisfactory long-term results ranging from 73\% (19) to $83 \%$ (20).

\section{SNM indications for fecal incontinence (FI) are as follows per ICS guidelines and American Society of Colon and Rectal Surgeons' (ASCRS) clinical practical guideline for the treatment of fecal incon- tinence:}

- According to the ICS guidelines: SNM should be considered as a second line treatment option for bothersome FI in patients who have failed conservative measures. (Level of Evidence: 2, Grade of Recommendation: B) (1);

- According to the American society of Colon and Rectal Surgeons, "Sacral neuromodulation may be considered as a first line surgical option for incontinent patients with and without sphincter defects. (Grade of Recommendation: Strong recommendation based on moderate-quality evidence, 1B) (21).

Both the ICS and the ASCRS consider SNM to be a first line surgical treatment for FI, even though the ICS considers SNM as a second line treatment, this is only because they consider conservative measures as a first line of treatment, but 
when considering a surgical option SNM is the first option.

The ICS and ASCRS both base their statements on the same evidence, that indicates that SNM has shown to reduce the frequency of FI episodes (22-26). They both quote a systematic review that showed that approximately 79\% (69\%$83 \%$ ) of patients experience $\geq 50 \%$ improvement in weekly FI episodes at 12 months follow up and $84 \%$ of patients experience $\geq 50 \%$ improvement at $>36$ months follow-up. It is worth noting that this review was only in patients who received a full system implant (26).

They both agree that the presence of a sphincter injury does not appear to impact the outcome of SNM (21). This is based on various studies that demonstrate that either an external or internal sphincter defect is not a formal contraindication for SNM (27-37).

The ICS goes further, by also stating that the size of the muscle defect does not affect decision making. This is because SNM relies more on sensory fiber stimulation than a motor response $(1,38,39)$.

Brouwer et al. (34) demonstrated that the presence of a pudendal neuropathy, a sphincter defect, or a previous sphincter repair did not affect the efficacy of SNM.

Even though there is excellent evidence proving long-term success, there is only one study that compares it to another surgical technique. This study shows a comparison between 15 patients with an SNM device and 15 control patients with an artificial bowel sphincter (ABS). Even though postoperative incontinence scores (Cleveland Clinic Florida fecal incontinence or CCF score) were moderately better in the (ABS) group, postoperative constipation scores were slightly worse and postoperative quality of life did not differ (40).

The ICS mentions a special group of patients that could benefit from SNM and these are patients with FI after a Low Anterior Resection for rectal cancer (1).

As time passes, treatment for rectal cancer improves and sphincter preservation strategies have been optimized. Many of these patients are cured of their cancer, but around 50-90\% will su- ffer bowel dysfunction and many of them will suffer low anterior resection syndrome (LARS), which includes FI, fecal urgency and frequent bowel movements, which could be very bothersome or even debilitating. (41-44) Because these patients have an anatomical alteration, it is still unclear how much benefit they may have with SNM in achieving symptomatic relief.

Two studies were conducted to establish whether SNM was a good option in patients with LARS. $47-100 \%$ of patients who had a basic SNM peripheral nerve evaluation (PNE) had success in symptomatic amelioration (42), but it has to be noted that the groups of patients were heterogeneous, so the information was difficult to analyze. Also, LARS is a syndrome that consists of different symptoms such as bowel movement clustering, urgency, and FI. Though most studies report an improvement in continence, future studies should include a more integral scoring system, like the LARS score (45), to understand which elements of the overall syndrome are improved by SNM.

The current recommendation by the ICS is that SNM should be considered after lifestyle modifications and medical treatment. (Level of Evidence: 3, Grade of Recommendation: D) (1).

Another interesting scenario where the ICS proposes SNM as a treatment option is in patients with combined bowel and urinary symptoms.

Two studies showed encouraging results regarding SNM in patients with mixed symptoms. One study of 14 patients showed excellent results in these patients who had FI associated with urinary symptoms (46). The second study, analyzed 24 patients who had both UI and FI, and showed symptomatic improvement in more than 30\% who used SNM with a mean follow up of 28 months. With this information, SNM could be helpful in a selected group of patients who have a combination of UI and FI, as it has showed significant improvement in both urinary and bowel symptom scores $(47,48)$.

Additionally, SNM has been studied in pediatric patients who have a combination of UI and FI and showed good results. Prospective clinical data and patient-reported measures, 29 patients, show an improvement that ranges between 5591\% (48). 
Even though the level of evidence is low (Level of Evidence: III, Grade of Recommendation: C) SNM is the preferred therapy for these patients (1).

SNM indications for Interstitial Cystitis (IC) /Bladder Pain Syndrome (BPS) as per ICS guidelines are as follows

IC/BPS is a condition characterized by urinary frequency, urgency, nocturia, but most importantly, bladder, urethral and pelvic pain (48). There is limited evidence supporting the use of SNM in patients with IC/BPS. Typically these are small observational case studies with different criteria for success. Nevertheless, SNM may be considered in patients with IC/BPS who do not sufficiently respond to first, second or third-line treatments. Based on these small observational studies, the success rate for SNM for IC/BPS was $48 \%$ to $72 \%$ (50-55).

Though SNM may be considered in IC/BPS as a fourth-line of treatment option there is minimal evidence reporting its efficacy in non IC/BPS chronic pelvic pain (56). Based on available studies, SNM cannot be recommended as a treatment option in these patients. However, pelvic pain is not a contraindication in patients with concomitant voiding symptoms such as urgency and frequency.

\section{POSSIBLE FUTURE INDICATIONS}

Constipation: A Cochrane systematic review done in 2015 showed a limited number of studies in this population and reported no important improvement of fecal frequency in the only crossover trial that compared SNM and sham stimulation in 59 patients with refractory constipation (57).

In a systematic review including 7 studies regarding SNM use for constipation and FI in a pediatric population, all studies indicated a significant improvement in constipation that was refractory to conservative medical treatment, with persistent enhancement in the following two years. Nevertheless, complication rates fluctuate between 17 and 50\% in all studies (58).
Neurogenic bladder: An important barrier for the use of SNM in patients with neurogenic bladder is the restriction related to the compatibility of InterStim with magnetic resonance imaging.

The actual InterStim model II 3058 is authorized for head only 1.5 Tesla MRI; therefore, current recommendations suggest the need for SNM explants in patients requiring MRI for a non-cranial indication. This is indicated to be the reason for removal in more than 23\% of InterStim removal surgeries, with $10 \%$ of the patients deciding to replace their devices at a later date (59).

Nevertheless, multiple studies have indicated that the use of MRI with the current SNM device is safe, including an exvivo phantom model which demonstrated that the intact system didn't undergo significant heating (60). Another study, by the same institution had 11 patients receive lumbar MRI with an intact system and recorded no adverse events (61). This limitation has motivated the research and development of new MRI-conditional equipment in the industry. Currently, the Axonics SNM system ${ }^{\mathrm{TM}}$,and a new InterStim model II with MRI-safe leads (SureScan leads)is available in many countries.

A number of studies have demonstrated the success of the Axonics system. The RELAX$-O A B$ trial, a multicenter prospective clinical trial of $51 \mathrm{OAB}$ patients treated with the Axonics SNM system $^{\mathrm{TM}}$ noted that $71 \%$ were responders at 4 weeks (62). Of those patients, 94\% continued to respond within 1 year, with an average reduction of 2.5 to 0.4 daily episodes of incontinence, and a decrease in urinary frequency episodes from 14 to 8 times per day.

In addition, total continence was achieved in 23\%. In addition the ARTISAN trial (discussed earlier) noted significant improvements as well. These short-term results are comparable with results using the InterStim ${ }^{\mathrm{TM}}$ SNM device. Further differences of the Axonics SNM system ${ }^{\mathrm{TM}}$ are a decreased size of the implantable pulse generator, MRI compatability and a rechargeable device.

The new InterStim model II with SureScan MRI-safe leads which is also MRI compatible, rechargeable and has a very small IPG is commercially available in some countries. 
Spinal cord injury: Sievert et al. published a case series of 4 patients subjected to SNM therapy shortly after a complete spinal cord injury who evolved to having no incontinence or detrusor overactivity (63).

This potential application of SNM could change the current practice in neurogenic bladder patients.

\section{TECHNIQUE POINTERS}

\section{Success}

The ICS guidelines state that "Clinicians should strive to achieve proper motor and/or sensory responses on all 4 contacts at stimulus amplitudes of $<2$ volts" (1).

A well-placed SNM lead should provide enough therapeutic stimulation from numerous electrodes and allow reprogramming a damaged electrode, should it be necessary (64).

A recent study, demonstrated that patients with greater electrode response scores had a lower probability of undergoing a device revision, and a lower likelihood of revision was evident with better toe motor response scores, though not bellows scores (65).

This may be explained by the fact that a great toe response depends essentially on a single muscle, while the pelvic bellows response may be generated from many muscles. Thus a toe response emulates stimulation of a minor and more therapeutically significant target nerve, whereas pelvic bellows appear stimulating any part of a broader target, perhaps various nerves (65).

Therefore, more precision should be taken when placing the lead to achieve a toe response, making this a better predictor of lead placement and a consecutive lower possibility of requiring a lead revision.

In 2011, a study by Peter et al. showed no improvement in therapeutic results nor diminution of revision rates with intraoperative sensory testing at the time of implantation (66), but assessing the motor response could be convenient for optimizing lead placement.

Correct lead placement is essential. The authors of a manuscript that shows the evolution of
SNM in urologic practice, emphasize that the leads should be placed superomedially, in the S3 foramina with outward lateral curvatures as these curves follow the anatomical course of the sacral nerve, and accomplishes responses during intraoperative testing at low amplitudes ( $<2$ volts) (67). This inherently achieves greater total electrode response score and a higher toe score which are both correlated to a decreased risk for device revision (65).

This decreased risk for revision probably results from an enhanced ability to "reprogram" around a defective or misplaced electrode to another one that gives therapeutic benefit, making it possible for the device to remain intact and avoiding a surgical revision (64).

Besides electrode movement, things like nervous system accommodation could also explain variations in efficacy of the original programmed electrode. In such occurrences, the substitute electrode should be adequately close to the target nerve to employ its effect, which could point out why having a larger number of electrode responses is protective from device revision (65).

Furthermore, as any SNM device will need battery replacement revision, optimizing lead positioning may aid by delaying the requirement of future revisions by not only enabling easier reprogramming, but also increasing its battery life. The closer the lead to the target nerve, the lower the amplitude needed to stimulate it. This also prolongs battery life and conserves device life. So, factors that optimize lead placement must be taken into consideration (65).

Research regarding SNM outcome optimization is greatly needed because as of today the only validated tool that measures correct lead placement is motor response, which is an indirect way to measure lead placement.

\section{FUTURE OF SACRAL NEUROMODULATION?}

The current implantable device (InterStim, Medtronic) has several weaknesses that need to be addressed. For instance, it is an expensive device, which explains the use of a staged-implant approach (1). Other noted deficiencies include battery life, lead fracture, MRI compatibility and clinician-de- 
pendent programming, which need to be improved, as does its long-term effect on bladder and bowel physiology (1). As noted above new devices that address some of these issues have recently become available.

Surgical technique has remained unchanged since the introduction of the tined-electrode, which disposed of the necessity to suture directly to the fascia. Nevertheless, there is an ongoing debate in regard to how accurately the lead must be positioned. There is evidence that suggests that only one active electrode is needed for a proper clinical response (68), but most studies encourage the use of 4-electrodes targeted at low voltages (69). CT supervision could be helpful in those with complex anatomical findings (69), but intraoperative EMG may also be of help in specific cases (70). Even so, more outcome-based research is needed to define the best method for introducing the lead.

Moreover, other than the 4-program settings and patient selection based on perceived symptom amelioration, specific programming recommendations are lacking.

New approaches may incorporate the patient's choice for a program, based on a real time bladder diary. Adding to this, smartphone apps are already available for patients to track their symptoms and could be used in device programming (71).

Economic modeling proposes that SNM becomes cost-effective in relation to intradetrusor botulinum toxin injections and to oral medical therapy for idiopathic $\mathrm{OAB}$ after 5 and 10 years respectively $(72,73)$. Nevertheless, there is little evidence on SNM cost-effectiveness relative to other therapies for fecal incontinence and urinary retention.

\section{CONFLICT OF INTEREST}

None declared.

\section{REFERENCES}

1. Goldman HB, Lloyd JC, Noblett KL, Carey MP, ño Botero JCC, Gajewski JB, et al. International continence society best practice statement for use of sacral neuromodulation. ICS Standards 2019; pp. 459-503. Available at. <https://www. ics.org/education/icsstandards>
2. de Groat WC. Anatomy of the central neural pathways controlling the lower urinary tract. Eur Urol. 1998;34(Suppl 1):2-5.

3. Griffiths D. Neural control of micturition in humans: a working model. Nat Rev Urol. 2015;12:695-705.

4. Griffiths D, Tadic SD, Schaefer W, Resnick NM. Cerebral control of the bladder in normal and urge-incontinent women. Neuroimage. 2007;37:1-7.

5. Komesu YM, Ketai LH, Mayer AR, Teshiba TM, Rogers RG. Functional $\mathrm{MRI}$ of the Brain in Women with Overactive Bladder: Brain Activation During Urinary Urgency. Female Pelvic Med Reconstr Surg. 2011;17:50-4.

6. Tadic SD, Griffiths D, Schaefer W, Murrin A, Clarkson B, Resnick NM. Brain activity underlying impaired continence control in older women with overactive bladder. Neurourol Urodyn. 2012;31:652-8.

7. Gill BC, Pizarro-Berdichevsky J, Bhattacharyya PK, Brink TS, Marks BK, Quirouet A, et al. Real-Time Changes in Brain Activity during Sacral Neuromodulation for Overactive Bladder. J Urol. 2017;198:1379-85.

8. [No authors]. Diagnosis and Treatment of NonNeurogenic Overactive Bladder (OAB) in Adults: an AUA/ SUFU Guideline (2019) - American Urological Association (Internet). (cited 2020 Jul 16). Available at. <https:// www.auanet.org/guidelines/overactive-bladder-(oab)guideline>

9. Hassouna MM, Siegel SW, Nÿeholt AA, Elhilali MM, van Kerrebroeck PE, Das AK, et al. A Sacral neuromodulation in the treatment of urgency-frequency symptoms: a multicenter study on efficacy and safety. J Urol. 2000;163:1849-54.

10. Siegel SW, Catanzaro F, Dijkema HE, Elhilali MM, Fowler CJ, Gajewski JB, et al. Long-term results of a multicenter study on sacral nerve stimulation for treatment of urinary urge incontinence, urgency-frequency, and retention. Urology. 2000;56(6 Suppl 1):87-91.

11. Schmidt RA, Jonas U, Oleson KA, Janknegt RA, Hassouna MM, Siegel SW, et al. Sacral nerve stimulation for treatment of refractory urinary urge incontinence. Sacral Nerve Stimulation Study Group. J Urol. 1999;162:352-7.

12. Herbison GP, Arnold EP. Sacral neuromodulation with implanted devices for urinary storage and voiding dysfunction in adults. Cochrane Incontinence Group, editor. Cochrane Database of Systematic Reviews (Internet). 2009 Apr 15 (cited 2020 Aug 23); Available from: http://doi.wiley.com/10.1002/14651858.

13. Amundsen $\mathrm{CL}$, Richter HE, Menefee SA, Komesu YM, Arya LA, Gregory WT, et al. OnabotulinumtoxinA vs Sacral Neuromodulation on Refractory Urgency Urinary Incontinence in Women: A Randomized Clinical Trial. JAMA. 2016;316:1366-74. 
14. McCrery R, Lane F, Benson K, Taylor C, Padron O, Blok $B$, et al. Treatment of Urinary Urgency Incontinence Using a Rechargeable SNM System: 6-Month Results of the ARTISAN-SNM Study. J Urol. 2020;203:185-92.

15. Jonas U, Fowler CJ, Chancellor MB, Elhilali MM, Fall M, Gajewski JB, et al. Efficacy of sacral nerve stimulation for urinary retention: results 18 months after implantation. J Urol. 2001;165:15-9.

16. van Kerrebroeck PE, van Voskuilen $A C$, Heesakkers JP, Lycklama á Nijholt AA, Siegel S, Jonas $U$, et al. Results of sacral neuromodulation therapy for urinary voiding dysfunction: outcomes of a prospective, worldwide clinical study. J Urol. 2007;178:2029-34.

17. Datta SN, Chaliha C, Singh A, Gonzales G, Mishra VC, Kavia $\mathrm{RB}$, et al. Sacral neurostimulation for urinary retention: 10year experience from one UK centre. BJU Int. 2008;101:192-6.

18. De Ridder D, Ost D, Bruyninckx F. The presence of Fowler's syndrome predicts successful long-term outcome of sacral nerve stimulation in women with urinary retention. Eur Urol. 2007;51:229-33; discussion 233-4.

19. Peeters K, Sahai A, De Ridder D, Van Der Aa F. Long-term follow-up of sacral neuromodulation for lower urinary tract dysfunction. BJU Int. 2014;113:789-94.

20. Siegel S, Noblett K, Mangel J, Griebling TL, Sutherland SE, Bird ET, et al. Results of a prospective, randomized, multicenter study evaluating sacral neuromodulation with InterStim therapy compared to standard medical therapy at 6-months in subjects with mild symptoms of overactive bladder. Neurourol Urodyn. 2015;34:224-30.

21. Paquette IM, Varma MG, Kaiser AM, Steele SR, Rafferty JF. The American Society of Colon and Rectal Surgeons' Clinical Practice Guideline for the Treatment of Fecal Incontinence. Dis Colon Rectum. 2015;58:623-36.

22. George AT, Kalmar K, Panarese A, Dudding TC, Nicholls RJ, Vaizey CJ. Long-term outcomes of sacral nerve stimulation for fecal incontinence. Dis Colon Rectum. 2012;55:302-6.

23. Hollingshead JR, Dudding TC, Vaizey CJ. Sacral nerve stimulation for faecal incontinence: results from a single centre over a 10-year period. Colorectal Dis. 2011;13:1030-4.

24. Matzel KE, Lux P, Heuer S, Besendörfer M, Zhang W. Sacral nerve stimulation for faecal incontinence: long-term outcome. Colorectal Dis. 2009;11:636-41.

25. Tjandra JJ, Chan MK, Yeh CH, Murray-Green C. Sacral nerve stimulation is more effective than optimal medical therapy for severe fecal incontinence: a randomized, controlled study. Dis Colon Rectum. 2008;51:494-502.

26. Thin NN, Horrocks EJ, Hotouras A, Palit S, Thaha MA, Chan $\mathrm{CL}$, et al. Systematic review of the clinical effectiveness of neuromodulation in the treatment of faecal incontinence. $\mathrm{Br}$ J Surg. 2013;100:1430-47.
27. Al Asari S, Meurette G, Mantoo S, Kubis C, Wyart V, Lehur PA. Percutaneous tibial nerve stimulation vs sacral nerve stimulation for faecal incontinence: a comparative casematched study. Colorectal Dis. 2014;16:0393-9.

28. Maeda Y, O'Connell PR, Lehur PA, Matzel KE, Laurberg S; European SNS Bowel Study Group. Sacral nerve stimulation for faecal incontinence and constipation: a European consensus statement. Colorectal Dis. 2015;17:074-87.

29. Johnson BL 3rd, Abodeely A, Ferguson MA, Davis BR, Rafferty JF, Paquette IM. Is sacral neuromodulation here to stay? Clinical outcomes of a new treatment for fecal incontinence. J Gastrointest Surg. 2015;19:15-9; discussion 19-20.

30. Conaghan P, Farouk R. Sacral nerve stimulation can be successful in patients with ultrasound evidence of external anal sphincter disruption. Dis Colon Rectum. 2005;48:1610-4.

31. Jarrett ME, Dudding TC, Nicholls RJ, Vaizey CJ, Cohen CR, Kamm MA. Sacral nerve stimulation for fecal incontinence related to obstetric anal sphincter damage. Dis Colon Rectum. 2008;51:531-7.

32. Melenhorst J, Koch SM, Uludag 0, van Gemert WG, Baeten CG. Is a morphologically intact anal sphincter necessary for success with sacral nerve modulation in patients with faecal incontinence? Colorectal Dis. 2008;10:257-62.

33. Boyle DJ, Knowles CH, Lunniss PJ, Scott SM, Williams NS, Gill KA. Efficacy of sacral nerve stimulation for fecal incontinence in patients with anal sphincter defects. Dis Colon Rectum. 2009;52:1234-9.

34. Brouwer R, Duthie G. Sacral nerve neuromodulation is effective treatment for fecal incontinence in the presence of a sphincter defect, pudendal neuropathy, or previous sphincter repair. Dis Colon Rectum. 2010;53:273-8.

35. Dudding TC, Parés D, Vaizey CJ, Kamm MA. Sacral nerve stimulation for the treatment of faecal incontinence related to dysfunction of the internal anal sphincter. Int $J$ Colorectal Dis. 2010;25:625-30.

36. Oom DM, Steensma AB, van Lanschot JJ, Schouten WR. Is sacral neuromodulation for fecal incontinence worthwhile in patients with associated pelvic floor injury? Dis Colon Rectum. 2010;53:422-7.

37. Ratto C, Litta F, Parello A, Donisi L, Doglietto GB. Sacral nerve stimulation is a valid approach in fecal incontinence due to sphincter lesions when compared to sphincter repair. Dis Colon Rectum. 2010;53:264-72.

38. Lundby L, Møller A, Buntzen S, Krogh K, Vang K, Gjedde A, et al. Relief of fecal incontinence by sacral nerve stimulation linked to focal brain activation. Dis Colon Rectum. 2011;54:318-23.

39. Carrington EV, Evers J, Grossi U, Dinning PG, Scott 
SM, O'Connell PR, et al. A systematic review of sacral nerve stimulation mechanisms in the treatment of fecal incontinence and constipation. Neurogastroenterol Motil. 2014;26:1222-37.

40. Meurette G, La Torre M, Regenet N, Robert-Yap J, Lehur PA. Value of sacral nerve stimulation in the treatment of severe faecal incontinence: a comparison to the artificial bowel sphincter. Colorectal Dis. 2009;11:631-5.

41. Juul T, Ahlberg M, Biondo S, Espin E, Jimenez LM, Matzel $\mathrm{KE}$, et al. Low anterior resection syndrome and quality of life: an international multicenter study. Dis Colon Rectum. 2014;57:585-91.

42. Thomas GP, Bradshaw E, Vaizey CJ. A review of sacral nerve stimulation for faecal incontinence following rectal surgery and radiotherapy. Colorectal Dis. 2015;17:939-42.

43. Ramage L, Qiu S, Kontovounisios C, Tekkis P, Rasheed S, Tan E. A systematic review of sacral nerve stimulation for low anterior resection syndrome. Colorectal Dis. 2015;17:762-71.

44. Eftaiha SM, Balachandran B, Marecik SJ, Mellgren A, Nordenstam J, Melich G, et al. Sacral nerve stimulation can be an effective treatment for low anterior resection syndrome. Colorectal Dis. 2017;19:927-33.

45. Emmertsen KJ, Laurberg S. Low anterior resection syndrome score: development and validation of a symptom-based scoring system for bowel dysfunction after low anterior resection for rectal cancer. Ann Surg. 2012;255:922-8.

46. Altomare DF, Rinaldi M, Petrolino M, Monitillo V, Sallustio $P$, Veglia A, et al. Permanent sacral nerve modulation for fecal incontinence and associated urinary disturbances. Int J Colorectal Dis. 2004;19:203-9.

47. El-Gazzaz G, Zutshi M, Salcedo L, Hammel J, Rackley R, Hull T. Sacral neuromodulation for the treatment of fecal incontinence and urinary incontinence in female patients: long-term follow-up. Int J Colorectal Dis. 2009;24:1377-81.

48. Gill BC, Swartz MA, Rackley RR, Moore CK, Goldman HB, Vasavada SP. Improvement of bowel dysfunction with sacral neuromodulation for refractory urge urinary incontinence. Int Urogynecol J. 2012;23:735-41.

49. Hanno P, Dmochowski R. Status of international consensus on interstitial cystitis/bladder pain syndrome/painful bladder syndrome: 2008 snapshot. Neurourol Urodyn. 2009;28:274-86.

50. Gajewski JB, Al-Zahrani AA. The long-term efficacy of sacral neuromodulation in the management of intractable cases of bladder pain syndrome: 14 years of experience in one centre. BJU Int. 2011;107:1258-64. Erratum in: BJU Int. 2016;117:E8

51. Maher CF, Carey MP, Dwyer PL, Schluter PL. Percutaneous sacral nerve root neuromodulation for intractable interstitial cystitis. J Urol. 2001;165:884-6.

52. Ghazwani YQ, Elkelini MS, Hassouna MM. Efficacy of sacral neuromodulation in treatment of bladder pain syndrome: long-term follow-up. Neurourol Urodyn. 2011;30:1271-5.

53. Marinkovic SP, Gillen LM, Marinkovic CM. Minimum 6-year outcomes for interstitial cystitis treated with sacral neuromodulation. Int Urogynecol J. 2011;22:407-12.

54. Powell CR, Kreder KJ. Long-term outcomes of urgencyfrequency syndrome due to painful bladder syndrome treated with sacral neuromodulation and analysis of failures. J Urol. 2010;183:173-6.

55. Comiter CV. Sacral neuromodulation for the symptomatic treatment of refractory interstitial cystitis: a prospective study. J Urol. 2003;169:1369-73.

56. Fariello JY, Whitmore K. Sacral neuromodulation stimulation for IC/PBS, chronic pelvic pain, and sexual dysfunction. Int Urogynecol J. 2010;21:1553-8.

57. Thaha MA, Abukar AA, Thin NN, Ramsanahie A, Knowles $\mathrm{CH}$. Sacral nerve stimulation for faecal incontinence and constipation in adults. Cochrane Database Syst Rev. 2015 Aug 24 (cited 2019 May 10);(8). Available at. <http://doi. wiley.com/10.1002/14651858.CD004464.pub3>.

58. lacona R, Ramage L, Malakounides G. Current State of Neuromodulation for Constipation and Fecal Incontinence in Children: A Systematic Review. Eur J Pediatr Surg. 2019;29:495-503.

59. Lloyd JC, Gill BC, Pizarro-Berdichevsky J, Goldman HB. Removal of Sacral Nerve Stimulation Devices for Magnetic Resonance Imaging: What Happens Next? Neuromodulation. 2017;20:836-40.

60. Quirouet A, Bhattacharyya PK, Dielubanza EJ, Gill BC, Jones SE, Goldman HB. Sacral Neuromodulation Device Heating During Lumbar and Pelvic Magnetic Resonance Imaging-a Phantom Study. Urology. 2017;107:61-6.

61. Guzman-Negron JM, Pizarro-Berdichevsky J, Gill BC, Goldman HB. Can Lumbosacral Magnetic Resonance Imaging be Performed Safely in Patients with a Sacral Neuromodulation Device? An In Vivo Prospective Study. J Urol. 2018;200:1088-92.

62. Blok B, Van Kerrebroeck P, de Wachter S, Ruffion A, Van der Aa F, Jairam R, et al. A prospective, multicenter study of a novel, miniaturized rechargeable sacral neuromodulation system: 12-month results from the RELAX-OAB study. Neurourol Urodyn. 2019;38:689-95.

63. Moore CK, Rueb JJ, Derisavifard S. What Is New in Neuromodulation? Curr Urol Rep. 2019; 20:55 Available at. <https://doi.org/10.1007/s11934-019-0920-6>.

64. Lenis AT, Gill BC, Carmel ME, Rajki M, Moore CK, Vasavada $S P$, et al. Patterns of hardware related electrode failures in sacral nerve stimulation devices. J Urol. 2013;190:175-9.

65. Pizarro-Berdichevsky J, Gill BC, Clifton M, Okafor HT, Faris AE, Vasavada SP, et al. Motor Response Matters: Optimizing Lead Placement Improves Sacral Neuromodulation Outcomes. J Urol. 2018;199:1032-6. 
66. Peters KM, Killinger KA, Boura JA. Is sensory testing during lead placement crucial for achieving positive outcomes after sacral neuromodulation? Neurourol Urodyn. 2011;30:1489-92.

67. Liberman D, Ehlert MJ, Siegel SW. Sacral Neuromodulation in Urological Practice. Urology. 2017;99:14-22.

68. Sterling ME, Hartigan SM, Wein AJ, Smith AL. A standardized surgical technique for removal of the Interstim tined lead. Can J Urol. 2016;23:8471-5.

69. Meissnitzer T, Trubel S, Posch-Zimmermann R, Meissnitzer MW. CT-Guided Lead Placement for Selective Sacral Neuromodulation to Treat Lower Urinary Tract Dysfunctions. AJR Am J Roentgenol. 2015;205:1139-42.

70. Taghva A, Romer J, Barolat G. Intraoperative electromyography as an adjunct to sacral neuromodulation for chronic pelvic pain. Neuromodulation. 2015;18:62-6; discussion 66 .
71. Abrams P, Paty J, Martina R, Newgreen DT, van Maanen $\mathrm{R}$, Paireddy $\mathrm{A}$, et al. Electronic bladder diaries of differing duration versus a paper diary for data collection in overactive bladder. Neurourol Urodyn. 2016;35:743-9.

72. Leong RK, de Wachter SG, Joore MA, van Kerrebroeck PE. Cost-effectiveness analysis of sacral neuromodulation and botulinum toxin A treatment for patients with idiopathic overactive bladder. BJU Int. 2011;108:558-64.

73. Arlandis S, Castro D, Errando C, Fernández E, Jiménez $M$, González $P$, et al. Cost-effectiveness of sacral neuromodulation compared to botulinum neurotoxin a or continued medical management in refractory overactive bladder. Value Health. 2011;14:219-28..
ARTICLE INFO

Departamento de Urologia,

Division de Obstetricia y Ginecologia,

Hospital Sótero del Río,

Pontificia Universidad Católica de Chile, Santiago, Chile

E-mail: javierpizarro@gmail.com

\author{
(iD) Javier Pizarro-Berdichevsky \\ https://orcid.org/0000-0002-8614-4480 \\ Int Braz J Urol. 2021; 47: 647-56
}

Submitted for publication: December 01, 2020

Accepted:

December 10, 2020 